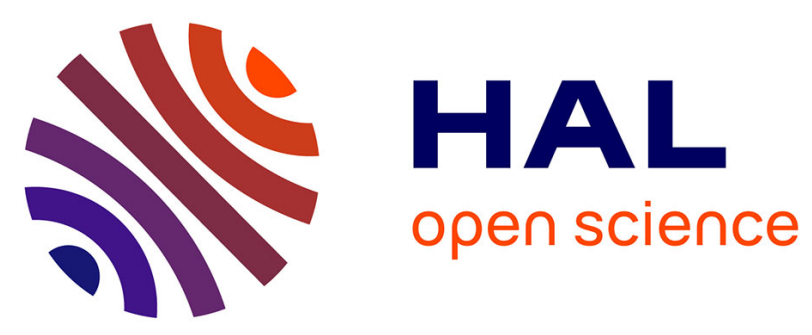

\title{
Towards automation of Collision Induced Unfolding experiments through online Size Exclusion Chromatography coupled to native Mass Spectrometry
}

Evolène Deslignière, Anthony Ehkirch, Thomas Botzanowski, Alain Beck, Oscar Hernandez-Alba, Sarah Cianférani

\section{To cite this version:}

Evolène Deslignière, Anthony Ehkirch, Thomas Botzanowski, Alain Beck, Oscar Hernandez-Alba, et al.. Towards automation of Collision Induced Unfolding experiments through online Size Exclusion Chromatography coupled to native Mass Spectrometry. Analytical Chemistry, 2020, 92 (19), pp.1290012908. 10.1021/acs.analchem.0c01426 . hal-02960860

\section{HAL Id: hal-02960860 https://hal.science/hal-02960860}

Submitted on 8 Oct 2020

HAL is a multi-disciplinary open access archive for the deposit and dissemination of scientific research documents, whether they are published or not. The documents may come from teaching and research institutions in France or abroad, or from public or private research centers.
L'archive ouverte pluridisciplinaire HAL, est destinée au dépôt et à la diffusion de documents scientifiques de niveau recherche, publiés ou non, émanant des établissements d'enseignement et de recherche français ou étrangers, des laboratoires publics ou privés. 
This document is confidential and is proprietary to the American Chemical Society and its authors. Do not copy or disclose without written permission. If you have received this item in error, notify the sender and delete all copies.

\section{Towards automation of Collision Induced Unfolding experiments through online Size Exclusion Chromatography coupled to native Mass Spectrometry}

\begin{tabular}{|r|l|}
\hline Journal: & Analytical Chemistry \\
\hline Manuscript ID & ac-2020-01426c.R2 \\
\hline Manuscript Type: & Article \\
\hline Date Submitted by the & n/a \\
\hline Complete List of Authors: & $\begin{array}{l}\text { Deslignière, Evolène; IPHC, Laboratoire de Spectrométrie de Masse } \\
\text { BioOrganique } \\
\text { Ehkirch, Anthony; IPHC, Laboratoire de Spectrométrie de Masse Bio- } \\
\text { Organique (LSMBO) } \\
\text { Botzanowski, Thomas; Northeastern University, } \\
\text { Beck, Alain; Centre d'Immunologie Pierre Fabre, Physico-Chemistry } \\
\text { Hernandez-Alba, Oscar; IPHC, Laboratoire de Spectrométrie de Masse } \\
\text { Bio-Organique (LSMBO) } \\
\text { Cianférani, Sarah; IPHC, Laboratoire de Spectrométrie de Masse Bio- } \\
\text { Organique (LSMBO) }\end{array}$ \\
\hline &
\end{tabular}

\section{SCHOLARONE Manuscripts}




\section{INTRODUCTION}

Native mass spectrometry (MS) is now broadly used in structural biology to characterize proteins, protein-protein complexes and protein-ligands interactions ${ }^{1}$. In the last decade, ion mobility (IM) combined with mass spectrometry has grown into a valuable asset for the study of proteins and noncovalent complexes ${ }^{2,3}$ mainly due to the implementation of IM, notably travelling wave ion mobility spectrometry ${ }^{4}$ (TWIMS), in commercially available mass spectrometers. TWIMS separates ions in the gas-phase based on their size, shape and charge under the influence of a low electric field. This new dimension provides structural information through arrival time distribution (ATD) which can be converted into rotationally averaged collision cross sections, the latter being related to the global conformation of the ions. However, IM fails to differentiate co-drifting species with closely related conformations due to its low resolution. Collision induced unfolding (CIU) approaches help to assess ion gas-phase unfolding, and appear as a promising alternative to circumvent poor IM separation ${ }^{6-8}$. In TWIMS instruments, CIU experiments are performed by raising collision voltages $(\mathrm{CVs})$ in the trap cell before IM separation, which induces further ion activation by energetic collisions with a trapping gas. As the accelerating voltage is increased, collisions become more energetic, leading to a build-up of internal energy in the ions ${ }^{6}$. Hence, ions may cross energy barriers and transition through a series of conformational intermediates in which the size of the ion can increase or decrease compared to the initial folded state, due to the unfolding or compaction of the protein'. These conformational changes are reflected through ATDs variations. Thereby, CIU experiments generate multi-dimensional datasets, with ATDs being acquired at each CV.

Early works on collisional activation were carried out by Shelimov et al. in 1997 and include the observation of apomyoglobin conformations ${ }^{10}$, and the different gasphase unfolding of cytochrome $c$ vs bovine pancreatic trypsin inhibitor which differ in their number of disulfide bridges (none and three, respectively)" Following the commercialization of quadrupole/TWIMS/time-of-flight mass spectrometers ${ }^{4}$, modern technological developments have further extended the range of CIU examples. Current 
applications of CIU encompass probing protein-protein complexes $^{12}$, 13, protein-ligand interactions ${ }^{9},{ }^{14-18}$, and binding of lipids to membrane proteins ${ }^{19}, 20$. CIU also plays a key role to investigate therapeutically-relevant proteins, allowing more conformational insights into monoclonal antibodies (mAbs) ${ }^{21-24}$, biosimilars ${ }^{25}$ and antibody-drugconjugates ${ }^{26,27}$. In particular, Tian et al. 7 demonstrated that subtle differences between intact mAbs subclasses, with different numbers and patterns of disulfide bridges, could be distinguished based on their gas-phase unfolding. Recently, Botzanowski et al. expanded this strategy to the middle-level classification of mAbs subclasses, which provides a more clear-cut categorization than the intact level ${ }^{28}$.

Even if native MS approaches have entered R\&D laboratories of biopharma companies, the use of CIU approaches is still scarce, mostly due to a lack of expertise required for this type of experiments but also because of a lack of automation of the CIU pipeline. Most efforts have been focused on the development of open-source software packages for CIU data treatment. CIU data are better visualized as unfolding plots, also named fingerprints, offering a unique representation of each protein's characteristics. ATDs are extracted at a selected mass-tocharge $(\mathrm{m} / \mathrm{z})$ ratio as a function of the applied CV. After normalization and smoothing at each CV, ATDs are stacked into a two-dimensional plot that can be generated using different programs ${ }^{9},{ }^{29-33}$. CIUSuite, CIUSuite 2, PULSAR and ORIGAMI ${ }^{\text {ANALYSE }}$ also provide direct comparison of fingerprints through root-mean-square deviation (RMSD) plots.

Although significant software developments have helped to ease and automate data interpretation, the main bottleneck of the CIU workflow remains its lack of automation for sample preparation (buffer exchange) and on-line data acquisition. Increase of $\mathrm{CV}$ is usually done either manually or in a semi automatic way using sequential data acquisition through a pre-programmed sample list. Altogether, the classical CIU data acquisition pipeline results in a tedious and time-consuming process which hampers its routine use. Classical "semi-automated" experiments (manual desalting followed by automated sequential acquisition) require around three hours ranging from sample preparation to data acquisition. Vallejo et al. ${ }^{34}$ suggested focusing only on median voltages of CIU features and transitions for faster mAbs differentiation, once full fingerprints have been established. Only one open-source software (ORIGAMIMS) allows automated acquisition of CIU data, but prior manual desalting is still necessary ${ }^{31}$.

In this context, the use of size exclusion chromatography (SEC) is of main interest for fast online desalting. Indeed, SEC has been successfully hyphenated to native MS for therapeutic protein analyses, allowing improved desalting efficiencies compared to manual desalting and offering the possibility for routine implementation of native MS approaches in the industry ${ }^{35}$. We thus explored the feasibility of SEC hyphenated to native IM-MS for CIU analyses.
We present here a fully automated CIU data acquisition setup, from buffer exchange to data interpretation, using SEC coupled to native IM-MS (SEC-CIU). We first developed and optimized the SEC-CIU method for different mAbs. Comparisons with classical nanoESI-CIU experiments pinpointed very similar fingerprints, proving the suitability of the SEC coupling for CIU automation. Overall, our SEC-CIU workflow allowed the highthroughput classification of mAbs subclasses at both intact and middle levels, while overall diminishing threefold the acquisition time necessary to record CIU experiments. Lastly, we demonstrated the potential of targeted scheduled SEC-CIU and multiplexed SEC-CIU to enhance information content in an even shorter amount of time.

\section{MATERIALS AND METHODS}

\section{Sample preparation.}

Adalimumab (Humira, Abbvie), ofatumumab (Arzerra, GSK), trastuzumab (Herceptin, Roche), panitumumab (Vectibix, Amgen), reslizumab (Cinqair, Teva) and nivolumab (Opdivo, BMS) were obtained from their respective manufacturers. Each intact $m A b$ was Ndeglycosylated by incubating one unit of IgGZERO (Genovis) per microgram of mAb, for $30 \mathrm{~min}$ at $37^{\circ} \mathrm{C}$. For middle-level enzymatic digestion, one unit of IdeS enzyme (FabRICATOR, Genovis) was added per microgram of mAb prior deglycosylation. The mixture was incubated at $37^{\circ} \mathrm{C}$ for 60 min.

\section{Manual buffer exchange.}

For ESI- and nanoESI- CIU experiments, samples were desalted against $100 \mathrm{mM}$ ammonium acetate at $\mathrm{pH}$ 7.0, using eight cycles of centrifugal concentrator (Vivaspin, 30 kDa cutoff, Sartorius, Göttingen, Germany). Protein concentration was then determined by UV absorbance using a NanoDrop spectrophotometer (Thermo Fisher Scientific, France). Each solution was diluted in $100 \mathrm{mM}$ ammonium acetate at $\mathrm{pH}$ 7.0 to $5 \mu \mathrm{M}$ prior to native ESIand nanoESI- CIU acquisitions.

\section{Native SEC-CIU experiments.}

An ACQUITY UPLC H-Class system (Waters, Manchester, UK) comprising a quaternary solvent manager, a sample manager set at $10{ }^{\circ} \mathrm{C}$, a column oven, and a TUV detector operating at $280 \mathrm{~nm}$ and $214 \mathrm{~nm}$ was hyphenated to a Synapt G2 HDMS mass spectrometer (Waters, Manchester, UK). The mobile phase used for online buffer exchange was composed of $100 \mathrm{mM}$ ammonium acetate at $\mathrm{pH}$ 7.o. Two SEC columns with different nominal lengths and pore sizes were evaluated: an Acquity BEH SEC 200Å, $1.7 \mu \mathrm{m}, 4.6 \times 300 \mathrm{~mm}$ and an Acquity BEH SEC $125 \AA$, $1.7 \mu \mathrm{m}, 4.6$ x $30 \mathrm{~mm}$ from Waters. For intact-level analyses performed on the $30 \mathrm{~mm}$ column, the flow rate was set to $0.250 \mathrm{~mL} / \mathrm{min}$ for $0.75 \mathrm{~min}$, decreased to $0.035 \mathrm{~mL} / \mathrm{min}$ for $3.35 \mathrm{~min}$, and raised to 0.250 $\mathrm{mL} / \mathrm{min}$ for $0.9 \mathrm{~min}$. The flow rate for middle-level analyses was set to $0.250 \mathrm{~mL} / \mathrm{min}$ for $0.80 \mathrm{~min}$, decreased to $0.035 \mathrm{~mL} / \mathrm{min}$ for $3.8 \mathrm{~min}$, and raised to $0.250 \mathrm{~mL} / \mathrm{min}$ 
for $0.4 \mathrm{~min}$. 20 and $12 \mu \mathrm{g}$ were injected for intact and middle level analyses, respectively.

The Synapt G2 was operated in sensitivity mode and positive polarity with a capillary voltage of $3.0 \mathrm{kV}$. Desolvation and source temperatures were set to 450 and $100{ }^{\circ} \mathrm{C}$, respectively. Desolvation and cone gas flow rates were 750 and $60 \mathrm{~L} / \mathrm{Hr}$, respectively. The cone voltage was fixed to $80 \mathrm{~V}$ to avoid in source ion activation while ensuring ion transmission. The backing pressure of the ZSpray source was set to 6 mbar. The Ar flow rate was 5 $\mathrm{mL} / \mathrm{min}$. Ions were focused in the helium cell $(120$ $\mathrm{mL} / \mathrm{min}$ ), prior to IM separation. In the IM cell, the $\mathrm{N}_{2}$ flow rate was $60 \mathrm{~mL} / \mathrm{min}$. The IM wave velocity and height were $800 \mathrm{~m} / \mathrm{s}$ and $40 \mathrm{~V}$, respectively. Data were acquired in the $1000-10000 \mathrm{~m} / \mathrm{z}$ range, without ion selection in the quadrupole.

Parameters for CIU experiments were defined in the MS File of the MassLynx v4.1 software (Waters, Manchester, UK). Collision voltages in the trap cell were increased from $\mathrm{o}$ to $200 \mathrm{~V}$ in $10 \mathrm{~V}$ steps. Each replicate of CIU fingerprints was acquired in three runs, corresponding to different MS files each containing seven IM-MS functions (o - 6o V, 70 $-130 \mathrm{~V}, 140-200 \mathrm{~V})$. For each voltage step of intact mAbs experiments, the number of scans and scan time were set to 5 and $3 \mathrm{~s}$, respectively. These $15 \mathrm{~s}$ acquisition slots, i.e. function slots, were aligned with the mAb elution, and the first and last functions were implemented at 1.75 and 3.37 min, respectively. For middle-level analyses, acquisition slots comprised 2 scans of $3 \mathrm{~s}$ each, with the first and last functions starting at 1.95 and $2.85 \mathrm{~min}$, respectively. Consecutive IM-MS functions were separated by $1.2 \mathrm{~s}$ intervals to ensure effective application and stable CVs.

\section{Native ESI-CIU experiments.}

Samples were infused to the electrospray source using a syringe infusion pump (KD Scientific, Holliston, MA, USA) using $250 \mu \mathrm{L}$ syringes (Hamilton, Bonaduz, Switzerland) at an infusion rate of $3.5 \mu \mathrm{L} / \mathrm{min}$. Desolvation and source temperatures were set to $450{ }^{\circ} \mathrm{C}$ and $100{ }^{\circ} \mathrm{C}$, respectively. The Synapt G2 was set up with the parameters previously described. Trap CVs were increased manually from o to 200 $\mathrm{V}$ in $10 \mathrm{~V}$ steps with 1-min acquisitions.

\section{Native nanoESI-CIU experiments.}

The Synapt G2 was coupled to the automated chip-based nanoESI device (TriVersa NanoMate, Advion, Ithaca, USA). The capillary voltage and the pressure of the nebulizer gas were set at $1.75 \mathrm{kV}$ and 0.55 psi, respectively. The source temperature was $100{ }^{\circ} \mathrm{C}$ while the desolvation gas was not heated. Other MS parameters were similar to those previously described. Trap CVs were increased manually from o to $200 \mathrm{~V}$ in $10 \mathrm{~V}$ steps with 1-min acquisitions.

\section{Data treatment.}

Chromatographic, IM and MS data were analyzed using MassLynx v4.1. CIU data were processed using the CIUSuite 2 v2.1 software ${ }^{33}$. Data sets were collected in triplicate (with three SEC runs for each replicate) to generate averaged CIU fingerprints. ATDs were smoothed using a Savitsky-Golay algorithm with a window length of 5 and a polynomial order of 2 . Interpolation by a factor of 2 allowed to double the number of steps along the CV axis. Averaged and differential plots with their associated RMSDs were generated using the 'Basic Analysis' module. RMSDs under $10 \%$ between technical replicates account for a good reproducibility of CIU data (Table $\mathrm{S} s$ ). Transitions between CIU features were quantitatively assessed by their corresponding $\mathrm{CIU}_{50}$ values using the CIUSuite 2 'Stability Analysis' module. Parameters used for feature detection (along with their median drift times) and CIU 50 analysis were as follows: standard mode for feature and $\mathrm{CIU}_{50}$ detections; minimum feature length $=2$ steps; feature allowed width (in mobility axis units) $=0.75 \mathrm{~ms}$; no CV gap length allowed within a feature; drift time spectrum = centroid at maximum value for each $\mathrm{CV}$; transition region padding $=15 \mathrm{~V}$. When features coexist at similar intensity across many voltages, the software only detects the most intense feature. In such cases, states can be better assessed and visualized by directly extracting ATDs at CVs of interest. Figures of stacked ATDs were generated with the ORIGAMI ${ }^{\text {ANALYSE }}$ v1.2.1.4 software $^{31}$.

For mAbs subclass categorization, the centroid of the ATDs were standardized at $\mathrm{CV}=\mathrm{o} \mathrm{V}$ to ensure comparison solely on unfolding patterns, irrespective of drift time variations due to different masses. Adalimumab (IgG1), panitumumab (IgG2) and reslizumab ( $\left.\mathrm{IgG}_{4}\right)$ were chosen as reference $m A b s$ to build classification methods at intact and middle levels using the 'Classification' module of the CIUSuite 2 software 33,36 . Univariate feature selection (UFS) plots were used to select the most diagnostic voltages, i.e. with the higher scores, to classify clusterized mAbs (ofatumumab, trastuzumab and nivolumab).

\section{RESULTS AND DISCUSSION}

\section{Development of the SEC-CIU workflow.}

In CIU experiments performed on TWIMS instruments, ions are activated in the trap collision cell by increasing collision voltages from o to $200 \mathrm{~V}$ prior to IM separation. CVs are ramped either manually or sequentially using a sample list, resulting in a error-prone and highly timeconsuming process ( 75 minutes for each sample, in triplicate, with $10 \mathrm{~V}$ steps). Previous manual CIU studies have been performed in nanoESI mode using either glass capillary nanoemitters 9 , 15-17 or automated chip-based nanoESI devices ${ }^{18,21,27,28}$. Both techniques hardly maintain spray stability throughout the whole $\mathrm{CV}$ ramp due to clogging $37,3^{8}$, leading to a laborious process for the MS operator. Hence, hyphenation of SEC to native IM-MS is of major interest to automate CIU experiments while substantially reducing the overall time process. Since online SEC coupling ensures a continuous controlled flow rate with a stable electrospray, CIU data can be recorded automatically during the sample elution.

\section{Optimization of SEC column.}

First, the choice of the SEC column length was decisive to significantly reduce the acquisition time. We compared two SEC columns, an Acquity BEH20o $4.6 \times 300 \mathrm{~mm}$ and 
an Acquity BEH125 $\mathrm{A}, 4.6 \times 30 \mathrm{~mm}$ (Waters), requiring runs of 18 and 5 minutes, respectively. Although the longer elution on the $300 \mathrm{~mm}$ column affords an increased number of scans and improved desalting efficiencies 35 , no significant difference was oberved on CIU fingerprints (RMSD $<6 \%$, Figure $\mathrm{S}_{1}$ ). Since data were of equal quality for both columns, the SEC-CIU methodology was developed and optimized on the $30 \mathrm{~mm}$ column to considerably speed up the process.

\section{Optimization of SEC flowrate.}

Automated SEC-native MS experiments for therapeutic proteins are usually performed at flow rates comprised between $0.10-0.25 \mathrm{~mL} / \mathrm{min}^{35}$. Online SEC-CIU first requires slowing down SEC flow rates in order to provide chromatographic peaks large enough to record several CV steps with a reasonable number of scans and scan time per $\mathrm{CV}$. However, great care must be taken to guarantee good signal-to-noise ratio and high enough IM-MS intensities even at low flow rate. In the case of mAbs at both intact and middle levels, we determined that $0.035 \mathrm{~mL} / \mathrm{min}$ was the best compromise between number of steps, scan parameters and IM-MS signal, leading to CIU data acquired for two minutes with enough MS intensity.

\section{Optimization of CIU parameters.}

CIU parameters, i.e. scan slots and trap $\mathrm{CV}$, are defined by the user within a single MassLynx MS file (Figure 1). One IM-MS function is implemented for each CV. Considering that MassLynx limits the number of recorded IM-MS functions to fifteen for a single analysis, two or three runs are necessary to cover the $\mathrm{o}-200 \mathrm{~V}$ range when using $10 \mathrm{~V}$ steps. Generally, CIU experiments are performed with 2, 5 or $10 \mathrm{~V}$ increments ${ }^{20,22,24}$, 39. In our hands, $10 \mathrm{~V}$ steps were enough to obtain well-resolved CIU fingerprints for an efficient identification of mAbs subclasses. After data processing in CIUSuite 2 (see Material and Methods), at least 8 specific diagnostic CVs were available for mAbs classifications. If needed, an additional run including appropriate CV values would help to better define highly populated regions or features that are only present in a narrow voltage range. Results and fingerprints presented thereafter were acquired with a three-runs method, which allows longer acquisition times for each $\mathrm{CV}$ and improves fingerprint resolution compared to two runs (Figure $\mathrm{S}_{2}$ ). In this method, runs contained seven IM-MS functions with $10 \mathrm{~V}$ steps to take full advantage of the chromatographic peak width while optimizing scan parameters. For intact mAbs, the acquisition time for each CV was set to $15 \mathrm{~s}$ (5 scans of 3 seconds) to improve the $\mathrm{S} / \mathrm{N}$ ratio. Once the run has started, CVs are automatically raised following the user's method. Of note, CVs can also be ramped in decreasing order without altering CIU fingerprints (Figure $\left.\mathrm{S}_{3}\right)$. For each of the three runs (o - 6o V, 70-130 V, $140-$ $200 \mathrm{~V})$, CIU data are stored within a single MassLynx.raw file compatible with the CIUSuite 2 software 33 for data analysis. Since ions are activated without prior selection in the quadrupole, different charge states are then available at once for fingerprint generation. The three output files are automatically combined to generate a complete CIU fingerprint $(\mathrm{o}-200 \mathrm{~V})$ corresponding to the extracted charge state. It is worth noting that three unique MS files can be used for SEC-CIU experiments as intact mAbs all exhibit the same elution time on $30 \mathrm{~mm}$ columns, thus enabling high-throughput analyses.

Overall, SEC-CIU offers a fast-online desalting 35 compared to classical nanoESI-CIU experiments which

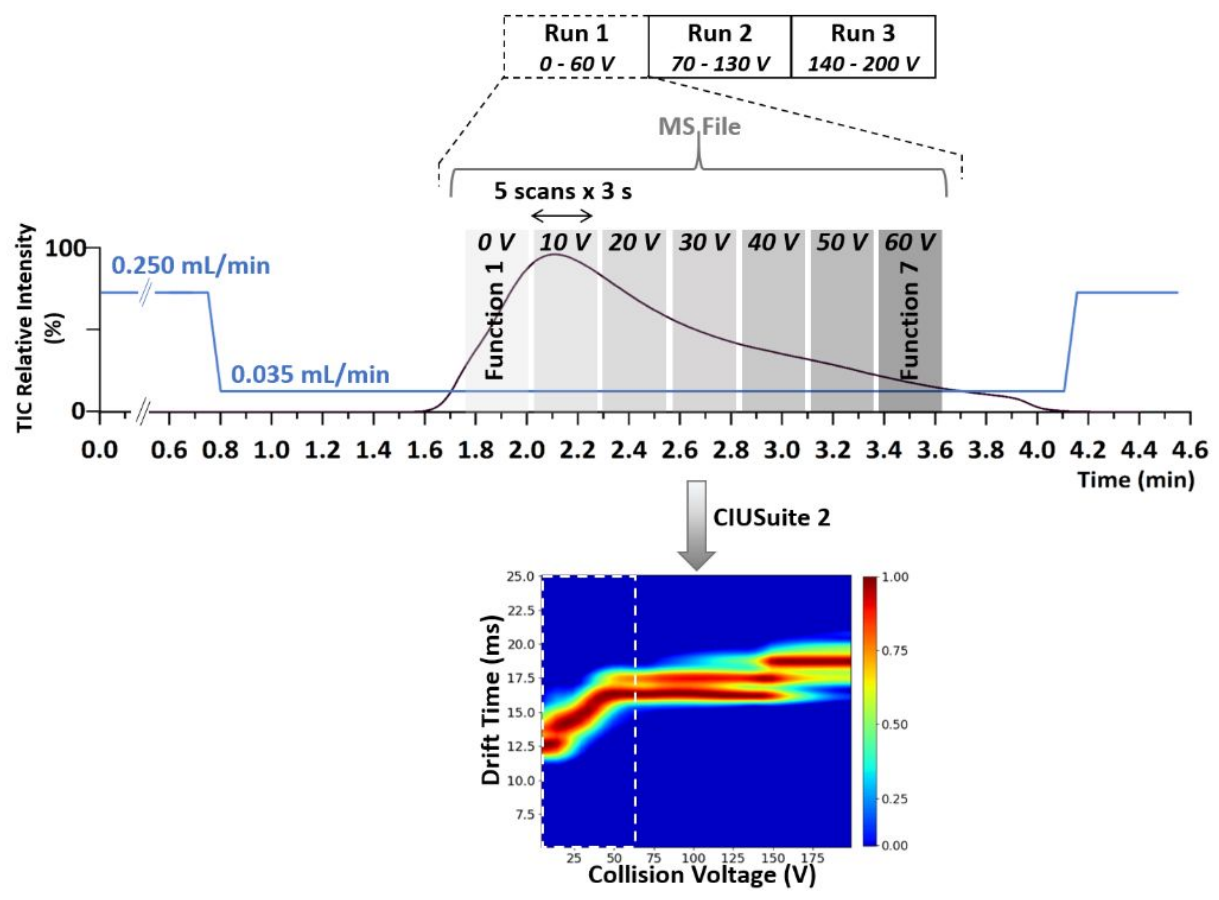

Figure 1. Schematic representation of the acquisition workflow of SEC-CIU data (o - 6o V range) for intact mAbs. For each collision voltage, one IM-MS function (greyscale bar) is implemented in the MassLynx MS file along the sample elution. Scans parameters were set to 5 scans of 3 seconds each. A three-runs method was used to generate a complete CIU replicate (o - 200 $\mathrm{V})$. Averaged unfolding plots are generated from three replicates, illustrated here by the CIU fingerprint of the $26+$ charge state of adalimumab. 
require manual buffer exchange, and the possibility to automate data acquisition to further reduce the data collection time saving two hours on average (depending on the desalting procedure used).

\section{Proof of concept of SEC-CIU for IgGi analysis.}

NanoESI-CIU experiments have previously been reported for the characterization of $\mathrm{mAbs}^{7,21-23,28}$. We first evaluated our online SEC-ESI-CIU method on adalimumab, a therapeutic $\mathrm{mAb}$ which belongs to the IgG1 subclass, and compared obtained fingerprints with nanoESI-CIU ones ${ }^{28}$ in order to assess whether CIU key features are retained with our SEC-CIU setup. As electrospray generates larger droplets with higher charge states than nanoESI37, only one charge state $(26+)$ was available for comparison between nanoESI- and SEC-ESICIU (Figure 2a). Both methods provided the same number of unfolding transitions (Figure $2 \mathrm{~b}, \mathrm{c}$ and e) and identical conformational states are obtained in both fingerprints (Figure $\mathrm{S}_{4} \mathrm{c}-\mathrm{e}$ ), but relative intensities between co-existing states slightly differ, which results in an apparent translation towards lower CVs for SEC-CIU (more obvious for transitions from state o to 1 and state 3 to 4 ) and leads to an RMSD $=15 \%$ between the two conditions (Figure S4a). For the $26+$ charge state of intact adalimumab, the first conformational state becomes the most intense at 20 $\mathrm{V}$ vs $30 \mathrm{~V}$ for nanoESI- and SEC-CIU, respectively (Figure 2e). While the third state was observed in both cases at the same voltage $(50 \mathrm{~V})$, the fourth conformational state again is already the main feature at $150 \mathrm{~V}$ for SEC-CIU but not until $190 \mathrm{~V}$ for nanoESI-CIU.

To rule out the possible effect of the SEC column to explain differences observed between SEC-ESI-CIU and nanoESI-CIU fingerprints, we recorded an additional CIU fingerprint with an ESI source under identical ESI conditions as for SEC-CIU (source and desolvation temperatures of $100{ }^{\circ} \mathrm{C}$ and $450^{\circ} \mathrm{C}$, respectively) except for the flow rate. Overall, very similar CIU fingerprints were obtained in SEC-ESI and ESI conditions (RMSD $<8 \%$, Figure $\mathrm{S}_{4} \mathrm{~b}$ and c), as depicted for the $26+$ charge state of adalimumab at the intact level (Figure $2 \mathrm{c}, \mathrm{d}$ and e), which demonstrates that the hyphenation of SEC to CIU does not significantly affect $\mathrm{mAb}$ CIU patterns.

MAbs being very stable molecules, we usually perform our native MS analyses in quite harsh temperature desolvation conditions, either in SEC-native MS35 or nanoESI-CIU ${ }^{21,28}$, to achieve more efficient desolvation resulting in subsequent better mass accuracy. We thus next evaluated the influence of source and desolvation temperatures on the nanoESI- and SEC-CIU fingerprints. No significant difference (RMSD $<9 \%$ for the $28+$ charge state) was observed between SEC-ESI-CIU fingerprints generated at $150{ }^{\circ} \mathrm{C}$ or $450{ }^{\circ} \mathrm{C}$ desolvation temperature (same number of conformational transitions and states) independently of the $\mathrm{mAb}$ subclass (Figure $\mathrm{S}_{5}$ ). These experiments confirm that quite harsh ESI temperature conditions do not strongly alter CIU patterns, as only intensities/ratios of the different conformational states are affected (Figure $\mathrm{S}_{5}$ ). NanoESI-CIU fingerprints recorded at source temperatures ranging from $40{ }^{\circ} \mathrm{C}$ to $100{ }^{\circ} \mathrm{C}$ also exhibit very similar CIU patterns (as deduced from median drift times, Figure S6) and only differ in terms of absolute $\mathrm{CIU}_{50}$ values, which are higher at $40{ }^{\circ} \mathrm{C}$ than $100{ }^{\circ} \mathrm{C}$, in agreement with less ion activation at lower temperature. Our results highlight that in the particular case of highly stable mAbs, quite harsh ESI or nanoESI temperature conditions do not significantly affect CIU fingerprints (in terms of number of transitions and median drift time values of the conformational states).

Altogether, SEC-CIU fingerprints provide the same level of information as nanoESI- or ESI- CIU.
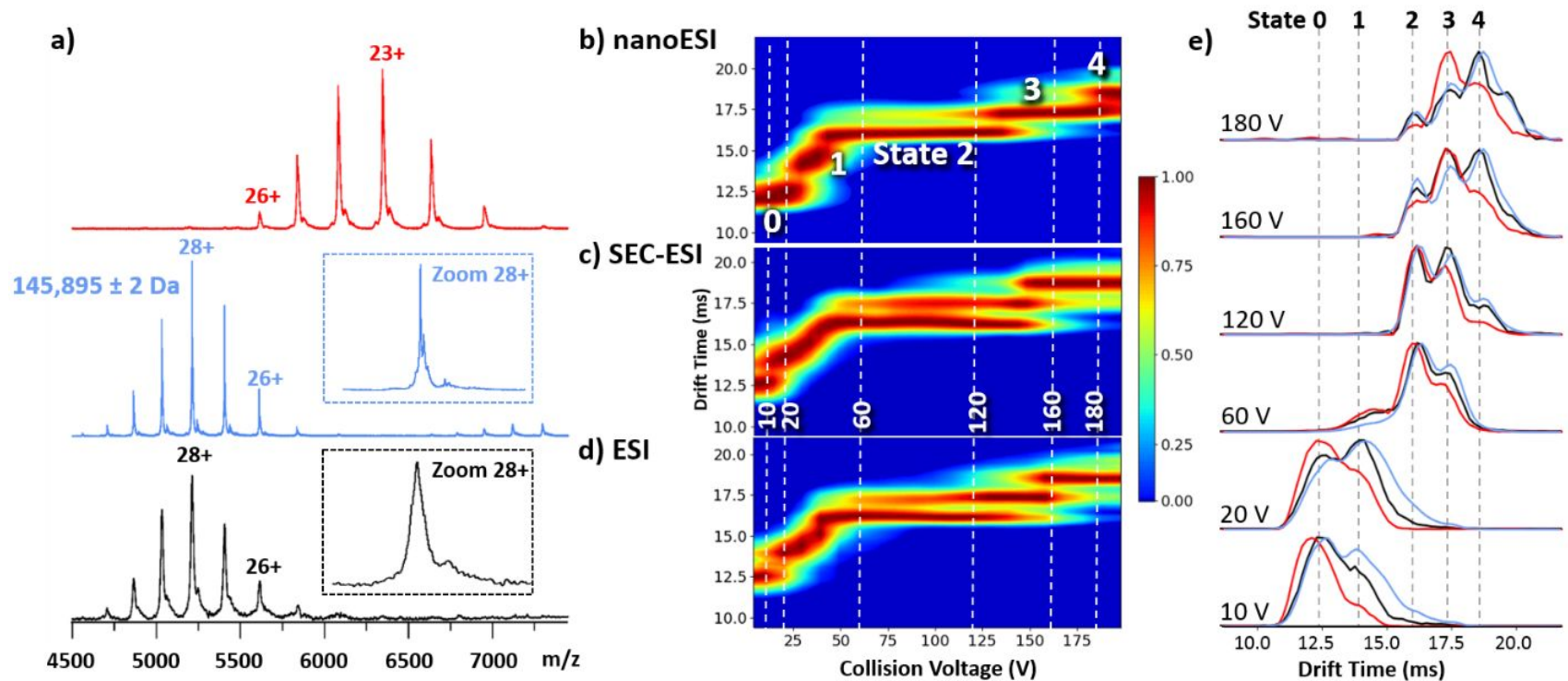

Figure 2. Comparison of nanoESI, SEC-ESI and ESI experiments. (a) Native mass spectra of intact adalimumab corresponding to nanoESI (red trace), SEC-ESI (blue trace) and ESI (black trace). Zooms on the $28+$ charge state are provided in insets for SEC-ESI and ESI mass spectra. CIU fingerprints of the $26+$ charge state of intact adalimumab obtained with (b) nanoESI, (c) SEC-ESI and (d) ESI infusion modes. (e) ATDs extracted at different voltages for nanoESI (red), SEC-ESI (blue) and ESI (black) are depicted in the right panel. 


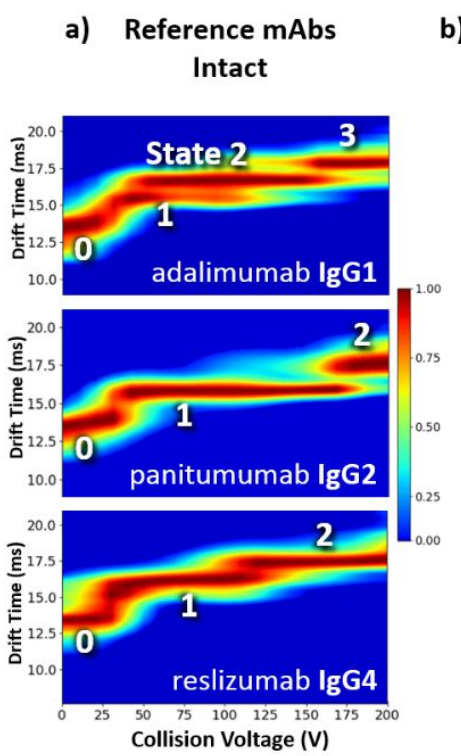

\section{b)}
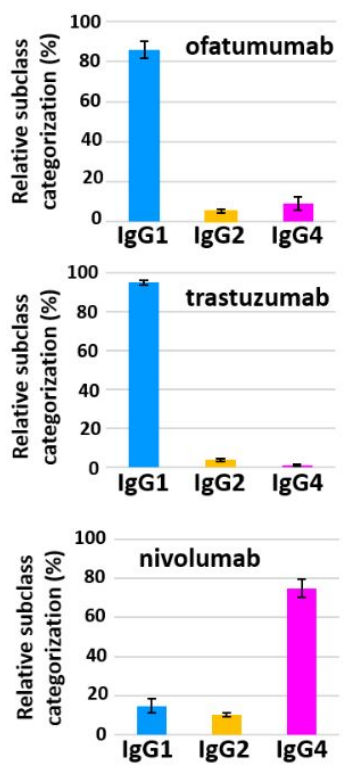

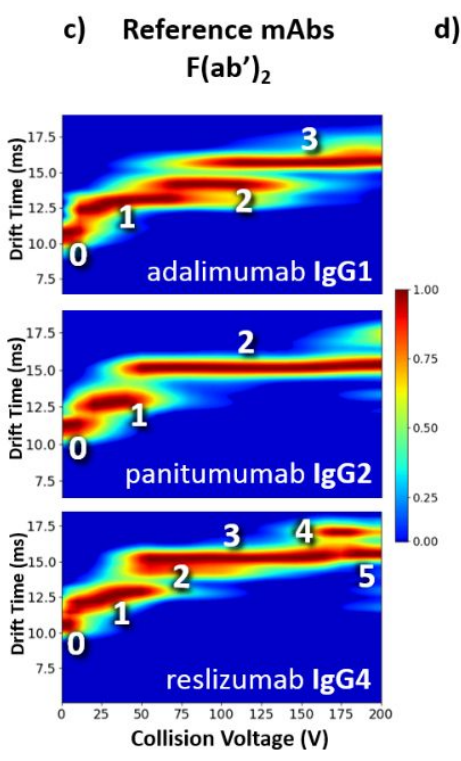

\section{d)}
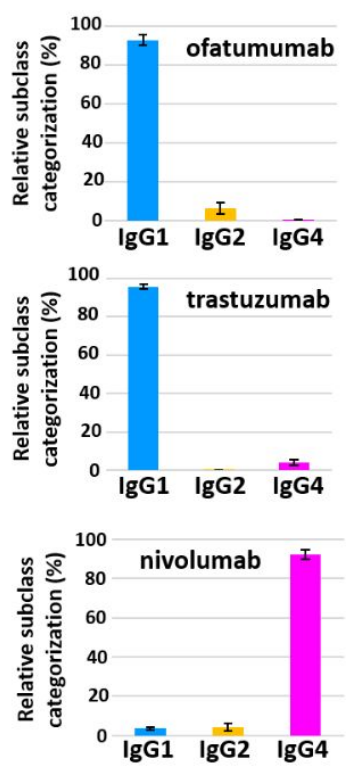

Figure 3. Intact and middle levels SEC-CIU experiments. (a) $27+$ charge state fingerprints of our three reference mAbs, adalimumab, panitumumab and reslizumab. (b) Subclass classification $\left(\mathrm{z}=27^{+}\right)$of ofatumumab $(\operatorname{IgG} 1)$, trastuzumab (IgG1) and nivolumab (IgG4) obtained with our in-house intact level classification method. (c) 21+ charge state fingerprints of $\mathrm{F}\left(\mathrm{ab}^{\prime}\right)_{2}$ fragments corresponding to our three reference mAbs. (d) Middle level subclass classification $(\mathrm{z}=21+)$ of ofatumumab (IgG1), trastuzumab (IgG1) and nivolumab (IgG4).

\section{SEC-CIU for mAb classification.}

Previous works have demonstrated that mAbs subclasses, which namely differ in their number and bridging of disulfide bonds, could be classified based on their unfolding patterns ${ }^{7,28}$. To benchmark our SEC-CIU strategy, we further applied it to the analysis of three mAbs belonging to different subclasses, adalimumab (IgG1), panitumumab ( $\left.\mathrm{IgG}_{2}\right)$ and reslizumab $\left(\mathrm{IgG}_{4}\right)$. At the intact level, all mAbs adopt a narrow charge state distribution $(26-30+)$. As the $27^{+}$charge state appears as the best compromise between native structure, signal intensity and CIU information content, it will be used thereafter for classification purposes (additional charge states are shown in supplementary data, Figures $\mathrm{S}_{7}$ and S8). SEC-CIU fingerprints obtained for the $27+$ charge state reveal three conformational transitions for the IgGi but only two transitions for IgG2 and $\mathrm{IgG}_{4}$ (Figure 3a). Although IgG2 and $\mathrm{IgG}_{4}$ exhibit the same number of transitions, mAbs subclasses could unambiguously be distinguished based on their specific ATDs profiles (with CIU 50 values of $36 \mathrm{~V}$ and $166 \mathrm{~V}$ for IgG2 vs $30 \mathrm{~V}$ and $117 \mathrm{~V}$ for IgG4) in agreement with Tian et al. observations 7 . The $27+$ charge state univariate feature selection (UFS) plot obtained with CIUSuite 2 shows that one diagnostic CIU region to differentiate subclasses is comprised between $90-125 \mathrm{~V}$ (Figure S9a). We subsequently built a classification method based on these specific CVs using the three mAbs previously analyzed as references.

To validate SEC-CIU for $\mathrm{mAb}$ subclass identification, we analyzed three additional mAbs (trastuzumab and ofatumumab - IgGis and nivolumab - IgG4) and subjected them to this automated classification. As already reported $^{21,28}$, although unfolding patterns between mAbs from the same subclass are not strictly identical, probably due to the contribution of the variable domains of $\left.\mathrm{F}(\mathrm{ab})_{2}\right)_{2}$ regions, the CIUSuite 2 module unambiguously recognizes ofatumumab and trastuzumab as IgGis $(86.0 \pm 4.3 \%$ and $94.9 \pm 1.2 \%$ of confidence, respectively), and nivolumab as an $\operatorname{IgG}_{4}(75.0 \pm 4.4 \%)$ (Figures $3 \mathrm{~b}$ and $\mathrm{Sgb}$ ). These results highlight the potential of our SEC-CIU workflow to classify $\mathrm{mAbs}$ at the intact level.

We next performed SEC-CIU experiments at the middlelevel after IdeS digestion. Botzanowski et al. reported that $\mathrm{CIU}$ fingerprints of $\left.\mathrm{F}(\mathrm{ab})_{2}\right)_{2}$ fragments are more informative than intact CIU fingerprints for mAbs subclass identification, whereas Fc subdomains do not allow clearcut classification due to similar unfolding patterns ${ }^{28}$. Since $\left.\mathrm{F}(\mathrm{ab})_{2}\right)_{2}$ and $\mathrm{Fc}$ fragments do not co-elute on the $30 \mathrm{~mm}$ column and could thus not be activated simultaneously, we focused our study on $\mathrm{F}\left(\mathrm{ab} \mathrm{b}_{2}\right)_{2}$ subunits to optimize data acquisition time. For the $21+$ charge state of the $F\left(a b^{\prime}\right)_{2}$ subdomain, only two conformational transitions are observed in the CIU fingerprint of the $\mathrm{IgG}_{2}$ (panitumumab), while three and five conformational transitions occur for $\mathrm{IgG}_{1}$ (adalimumab) and $\mathrm{IgG}_{4}$ (reslizumab), respectively (Figure $3 \mathrm{c}$ ). Results obtained in terms of transitions for charge states 21 and 22+ (Figure S1o) were consistent with IgG2s being less prone to unfolding compared to other subclasses due to two additional disulfide bridges in the hinge region. Again, $\mathrm{mAb}$ subclasses could clearly be differentiated by comparing their unfolding patterns (Figure Si1). The UFS plot of the $\mathrm{F}\left(\mathrm{ab}^{\prime}\right)_{2} 21+$ charge state pinpoints diagnostic CIU collision voltages in the $85-120 \mathrm{~V}$ range (Figure S9c). Our middle-level classification based on the three reference mAbs (adalimumab, panitumumab and reslizumab) unequivocally categorizes ofatumumab and trastuzumab as IgGis ( $92.8 \pm 2.7 \%$ and $95.6 \pm 1.2 \%)$, and nivolumab as an $\mathrm{IgG}_{4}(92.2 \pm 2.5 \%)$ (Figures $3 \mathrm{~d}$ and S9d). Scores 
obtained were similar (> 90 \%) to $\mathrm{F}(\mathrm{ab})_{2}$-classification using manual CIU fingerprints ${ }^{28}$. Higher scores achieved after IdeS digestion compared to the intact level confirm that $\mathrm{mAb}$ subclass categorization is more accurate at the middle level, in agreement with Botzanowski et al. ${ }^{28}$.

Once full CIU-fingerprints $(\mathrm{o}-200 \mathrm{~V})$ of reference $\mathrm{mAbs}$ have been generated and classification parameters optimized, we developed a targeted scheduled SEC-CIU based on the most diagnostic CVs extracted from UFS plots33. This allowed us to propose a single-run SEC-CIU strategy for rapid IgGs classification (15 minutes for triplicate CIU maps) by recording only 7 diagnostic CVs (in $5 \mathrm{~V}$ steps, 90 to $120 \mathrm{~V}$ for $\mathrm{z}=27+$ at intact level, or 85 and 95 to $120 \mathrm{~V}$ for $\mathrm{z}=21+$ at middle level), with scan parameters identical to Figure 1. This method provides classification scores $>85 \%$ at both intact and middle levels for trastuzumab and nivolumab (Figure S12). Targeted scheduled single-run SEC-CIU preserves key information for mAbs categorization, and also affords a drastic reduction of the overall acquisition time.

Altogether, our results highlight the suitability of SEC$\mathrm{CIU}$ for fast $\mathrm{mAb}$ classification at both intact and middle level, while offering a characterization as precise as nanoESI-CIU experiments but with a considerable reduction of the acquisition time.

\section{SEC-CIU for mAbs-multiplexed analyses.}

An additional benefit of short SEC columns stems from the co-elution of intact mAbs that enables their simultaneous activation in the trap cell. Performing SECCIU experiments without prior ion isolation in the quadrupole thus allows to acquire CIU data for different proteins at once, while also covering their entire charge state distributions in the meantime. Of course, mAbs should feature distinct $\mathrm{m} / \mathrm{z}$ ratio to avoid overlapping CIU fingerprints. The characterization of mAbs mixtures is of key interest, as co-formulated mAbs with synergic effects represent promising therapeutic entities ${ }^{40,41}$.

In order to fully exploit the potential of SEC-CIU for fast $\mathrm{mAb}$ classification, we subsequently aimed at analyzing the three $m A b s$ subclasses in a single experiment. We thus evaluated our SEC-CIU strategy on a mixture containing intact ofatumumab (IgG1), panitumumab ( $\mathrm{IgG}_{2}$ ) and nivolumab $\left(\mathrm{IgG}_{4}\right)$. Online SEC desalting provided wellresolved MS peaks for the three mAbs (Figure 4a). In our case, MS peaks exhibit an average FWHM of $15 \mathrm{~m} / \mathrm{z}$ for the $27+$ charge state of intact mAbs, which corresponds to a resolution of $\sim 310$ over the $5300-5500 \mathrm{~m} / \mathrm{z}$ range.

Consequently, in order to ensure enough separation of two consecutive peaks, we mixed deglycosylated mAbs with a mass difference higher than $450 \mathrm{Da}$ to avoid fingerprint interferences. The quality of the separation allowed to extract ATDs at $\mathrm{m} / \mathrm{z}$ ranges specific to each
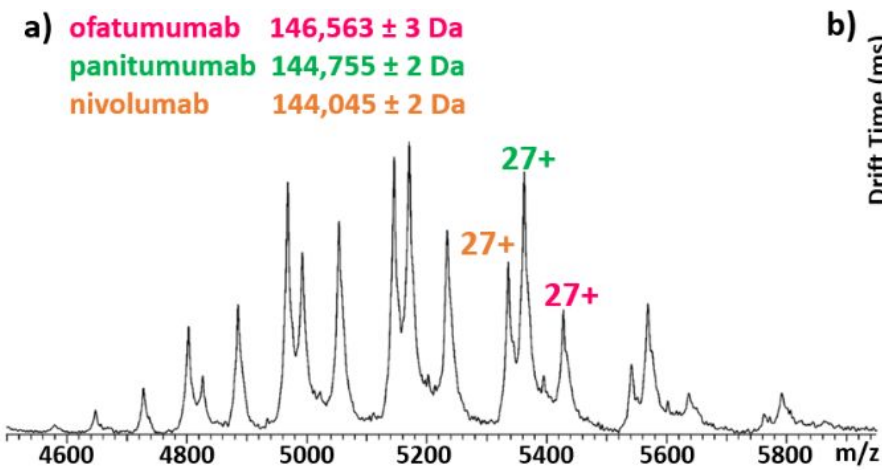

b)

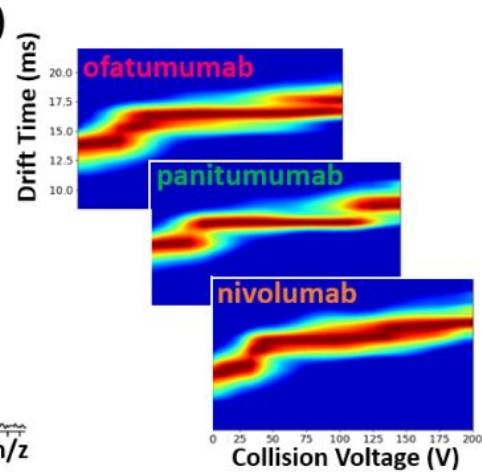

c)

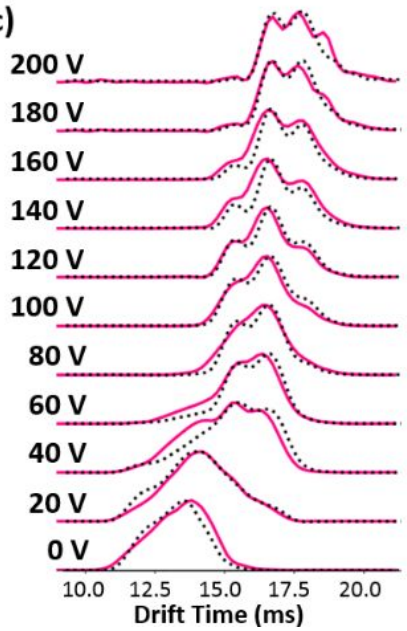

d)

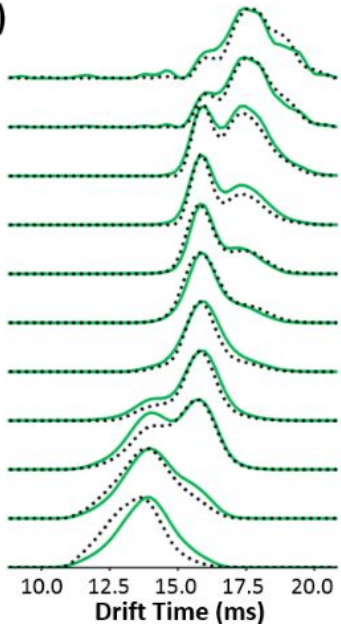

e)

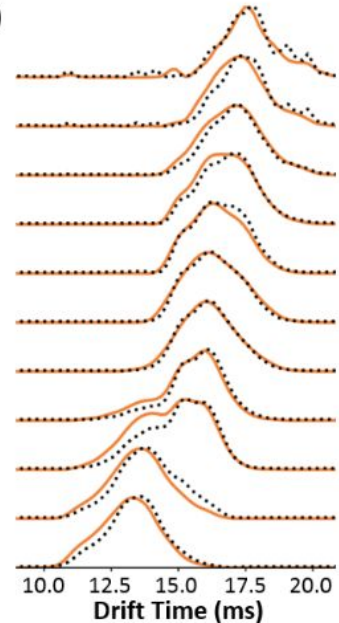

Figure 4. MAbs-multiplexed SEC-CIU experiments. (a) Native SEC-CIU mass spectrum of an equimolar ( $15 \mu \mathrm{M}) \mathrm{mAb}$ mixture containing three intact mAbs, ofatumumab, panitumumab and nivolumab (trap CV $=90 \mathrm{~V}$ ). (b) $27+$ charge state SEC-CIU fingerprints of each intact $\mathrm{mAb}$ subclass obtained from the mAb mixture. (c, d, e) ATDs were extracted in $20 \mathrm{~V}$ steps from o to 200 $\mathrm{V}$, allowing the comparison of unfolding processes of single-mAb (dotted lines) and mAbs-multiplexed SEC-CIU (solid lines) experiments at intact level. 
$\mathrm{mAb}$, resulting in well-defined CIU fingerprints which still afford an unambiguous subclass classification (Figure 4 b). An issue of quadrupole non-selected CIU lies in possible interferences between species activated in the trap cell which might influence unfolding transitions ${ }^{20,34}$. Thereby, CIU data obtained from the mAb mixture were compared with those acquired using single-mAb experiments to assess whether multiplexing alters CIU profiles. For each of the three subclasses, the superposition of ATDs demonstrated that the presence of other mAbs in the sample matrix does not compromise the unfolding process (Figure 4c-e). Overall, multiplexed SEC-CIU experiments can easily be implemented for mAbs mixture analysis provided enough MS resolution.

Altogether, mAbs-multiplexed experiments provide significant improvements over standard CIU approaches. Our method offers a wide range of information, i.e. fingerprints of multiple proteins and their different charge-states, while reducing data acquisition time (same time for one to three $\mathrm{mAbs}$ analyses). As $\mathrm{F}\left(\mathrm{ab}{ }^{\prime}\right)_{2}$ fragments also co-elute on the $30 \mathrm{~mm}$ SEC column, our multiplexing strategy can be further expanded to the middle-level for mAbs subclass classifications (Figure $\mathrm{S}_{13}$ ).

\section{CONCLUSIONS}

We have demonstrated here the potential of online hyphenation of SEC to native IM-MS for the automation of CIU experiments. In our hands, the combination of improved and fast online desalting and automated data collection afforded by our SEC-CIU workflow considerably shortens the overall time process (from 3 hours to 15 minutes for targeted scheduled SEC-CIU). SEC-CIU eases data acquisition while preserving the quality and key features (number of conformational transitions) of nanoESI-CIU fingerprints. Our method proved to be efficient for rapid mAb subclasses identification, providing specific signatures of each subclass at both intact and middle levels. In addition, either targeted scheduled CIU method relying on diagnostic trap CVs or mAb multiplexing allowed us to extend SEC-CIU to even more complex samples analyses, widening the scope of information available within one SEC-CIU experiment.

Altogether, we believe that online SEC-CIU will promote the integration of CIU in analytical workflows for routine biotherapeutics characterization. SEC-CIU appears as an asset to rapidly assess protein gas-phase unfolding. Therefore, we envision that further developments to automate data acquisition and interpretation will usher in the implementation of CIU approaches in $\mathrm{R} \& \mathrm{D}$ laboratories.

\section{ASSOCIATED CONTENT}

Supporting Information. The Supporting Information is available free of charge at http://pubs.acs.org.

Table S1, RMSDs of technical SEC-CIU replicates; Figure S1, SEC-CIU fingerprints on 300 vs $30 \mathrm{~mm}$ SEC columns; Figure S2, SEC-CIU fingerprints with 2 vs 3 runs; Figure $S_{3}$, SEC-CIU fingerprints with increasing vs decreasing CVs; Figure $\mathrm{S}_{4}$, Comparisons beween nanoESI-/SEC-ESI- CIU;
Figure $\mathrm{S}_{5}$, Influence of ESI desolvation temperature on SEC-CIU fingerprints; Figure S6, Influence of source temperature on nanoESI-CIU fingerprints; Figures $\mathrm{S}_{7}-\mathrm{S}_{10}$, Additional SEC-CIU fingerprints and classifications; Figure S11, ATDs of $\mathrm{F}\left(\mathrm{ab}^{\prime}\right)_{2}$ for reference mAbs; Figure S12, Targeted scheduled SEC-CIU classifications; Figure S13, Middle-level mAbs-multiplexed SEC-CIU.

\section{AUTHOR INFORMATION}

\section{Corresponding Author}

*Phone: +33 (o)3 688526 79. Fax: +33 (o) 368852781.

*E-mail: sarah.cianferani@unistra.fr

\section{Author Contributions}

The manuscript was written through contributions of all authors. All authors have given approval to the final version of the manuscript.

\section{Notes}

The authors declare no competing financial interest.

\section{ACKNOWLEDGMENT}

This work was supported by the CNRS, the University of Strasbourg, the "Agence Nationale de la Recherche" and the French Proteomic Infrastructure (ProFI; ANR-10INBS-08-03). The authors would like to thank GIS IBiSA and Région Alsace for financial support in purchasing a Synapt G2 HDMS instrument. E.D., A.E., T.B. and O.A.-H. acknowledge the French Ministry for Education and Research, the Institut de Recherches Internationales Servier, the "Association Nationale de la Recherche et de la Technologie" (ANRT) and Syndivia, and the IdeX program of the University of Strasbourg for funding of their $\mathrm{PhD}$ and postdoctoral fellowship, respectively.

\section{ABBREVIATIONS}

ATD, arrival time distribution; CCS, collision cross section; $\mathrm{CIU}$, collision induced unfolding; $\mathrm{CV}$, collision voltage; $\mathrm{ESI}$, electrospray; $\left.\mathrm{F}(\mathrm{ab})_{2}\right)_{2}$, full fragment antigen-binding; Fc, fragment crystallizable; IgG, immunoglobulin G; IM, ion mobility; mAb, monoclonal antibody; MS, mass spectrometry; SEC, size exclusion chromatography; TWIMS, travelling wave ion mobility spectrometry.

\section{REFERENCES}

1. Leney, A. C.; Heck, A. J., Native Mass Spectrometry: What is in the Name? J Am Soc Mass Spectrom 2017, 28 (1), 5-13.

2. Goth, M.; Pagel, K., Ion mobility-mass spectrometry as a tool to investigate protein-ligand interactions. Anal Bioanal Chem 2017, 409 (18), 4305-4310.

3. $\quad$ Eschweiler, J. D.; Kerr, R.; Rabuck-Gibbons, J.; Ruotolo, B. T., Sizing Up Protein-Ligand Complexes: The Rise of Structural Mass Spectrometry Approaches in the Pharmaceutical Sciences. Annu Rev Anal Chem 2017, 10, 25-44.

4. $\quad$ Pringle, S. D.; Giles, K.; Wildgoose, J. L.; Williams, J. P.; Slade, S. E.; Thalassinos, K.; Bateman, R. H.; Bowers, M. T.; Scrivens, J. H., An investigation of the mobility separation of some peptide and protein ions using a new hybrid quadrupole/travelling wave IMS/oaToF instrument. Int J Mass Spectrom 2007, 261 (1), 1-12.

5. Gabelica, V.; Marklund, E., Fundamentals of ion mobility spectrometry. Curr Opin Chem Biol 2018, 42, 51-59. 
6. Dixit, S. M.; Polasky, D. A.; Ruotolo, B. T., Collision induced unfolding of isolated proteins in the gas phase: past, present, and future. Curr Opin Chem Biol 2018, 42, 93-10o.

7. Tian, Y.; Han, L.; Buckner, A. C.; Ruotolo, B. T., Collision Induced Unfolding of Intact Antibodies: Rapid Characterization of Disulfide Bonding Patterns, Glycosylation, and Structures. Anal Chem 2015, 87 (22), 11509-15.

8. Tian, Y. W.; Ruotolo, B. T., Collision induced unfolding detects subtle differences in intact antibody glycoforms and associated fragments. Int J Mass Spectrom 2018, 425, 1-9.

9. $\quad$ Allison, T. M.; Reading, E.; Liko, I.; Baldwin, A. J.; Laganowsky, A.; Robinson, C. V., Quantifying the stabilizing effects of protein-ligand interactions in the gas phase. Nat Commun 2015, 6, 8551.

10. Shelimov, K. B.; Jarrold, M. F., Conformations, unfolding, and refolding of apomyoglobin in vacuum: An activation barrier for gas-phase protein folding. J Am Chem Soc 1997, 119 (13), 2987-2994. 11. Shelimov, K. B.; Clemmer, D. E.; Hudgins, R. R.; Jarrold, M F., Protein Structure in Vacuo: Gas-Phase Conformations of BPTI and Cytochrome c. J Am Chem Soc 1997, 119 (9), 2240-2248.

12. Rabuck-Gibbons, J. N.; Lodge, J. M.; Mapp, A. K.; Ruotolo, B. T., Collision-Induced Unfolding Reveals Unique Fingerprints for Remote Protein Interaction Sites in the KIX Regulation Domain. J Am Soc Mass Spectrom 2019, 30 (1), 94-102.

13. Mehmood, S.; Marcoux, J.; Gault, J.; Quigley, A.; Michaelis, S.; Young, S. G.; Carpenter, E. P.; Robinson, C. V., Mass spectrometry captures off-target drug binding and provides mechanistic insights into the human metalloprotease ZMPSTE24. Nat Chem 2016, 8 (12), 1152-1158.

14. Hopper, J. T.; Oldham, N. J., Collision induced unfolding of protein ions in the gas phase studied by ion mobility-mass spectrometry: the effect of ligand binding on conformational stability. J Am Soc Mass Spectrom 2009, 20 (10), 1851-8.

15. Rabuck, J. N.; Hyung, S. J.; Ko, K. S.; Fox, C. C.; Soellner, M. B.; Ruotolo, B. T., Activation state-selective kinase inhibitor assay based on ion mobility-mass spectrometry. Anal Chem 2013, 85 (15), 6995-7002.

16. Niu, S.; Ruotolo, B. T., Collisional unfolding of multiprotein complexes reveals cooperative stabilization upon ligand binding. Protein Sci 2015, 24 (8), 1272-81.

17. Fantin, S. M.; Parson, K. F.; Niu, S.; Liu, J.; Polasky, D. A.; Dixit, S. M.; Ferguson-Miller, S. M.; Ruotolo, B. T., Collision Induced Unfolding Classifies Ligands Bound to the Integral Membrane Translocator Protein. Anal Chem 2019, 91 (24), 15469-15476.

18. Veale, C. G. L.; Mateos Jimenez, M.; Mackay, C. L.; Clarke, D. J., Native Ion Mobility Mass Spectrometry (IM-MS) reveals that small organic acid fragments impart gas-phase stability to carbonic anhydrase II. Rapid Commun Mass Spectrom 2019.

19. Laganowsky, A.; Reading, E.; Allison, T. M.; Ulmschneider, M. B.; Degiacomi, M. T.; Baldwin, A. J.; Robinson, C. V., Membrane proteins bind lipids selectively to modulate their structure and function. Nature 2014, 510 (7503), 172-175.

20. Liu, Y.; Cong, X.; Liu, W.; Laganowsky, A., Characterization of Membrane Protein-Lipid Interactions by Mass Spectrometry Ion Mobility Mass Spectrometry. J Am Soc Mass Spectrom 2017, 28 (4), 579-586.

21. Hernandez-Alba, O.; Wagner-Rousset, E.; Beck, A.; Cianferani, S., Native Mass Spectrometry, Ion Mobility, and CollisionInduced Unfolding for Conformational Characterization of $\mathrm{IgG}_{4}$ Monoclonal Antibodies. Anal Chem 2018, 90 (15), 8865-8872.

22. Campuzano, I. D. G.; Larriba, C.; Bagal, D.; Schnier, P. D., Ion Mobility and Mass Spectrometry Measurements of the Humanized IgGk NIST Monoclonal Antibody. 2015, 1202, 75-112.

23. Ferguson, C. N.; Gucinski-Ruth, A. C., Evaluation of Ion Mobility-Mass Spectrometry for Comparative Analysis of Monoclonal Antibodies. J Am Soc Mass Spectr 2016, 27 (5), 822-833.

24. Watanabe, Y.; Vasiljevic, S.; Allen, J. D.; Seabright, G. E.; Duyvesteyn, H. M. E.; Doores, K. J.; Crispin, M.; Struwe, W. B., Signature of Antibody Domain Exchange by Native Mass Spectrometry and Collision-Induced Unfolding. Anal Chem 2018, 90 (12), $7325-7331$.
25. Pisupati, K.; Tian, Y.; Okbazghi, S.; Benet, A.; Ackermann, R.; Ford, M.; Saveliev, S.; Hosfield, C. M.; Urh, M.; Carlson, E.; Becker, C.; Tolbert, T. J.; Schwendeman, S. P.; Ruotolo, B. T.; Schwendeman, A., A Multidimensional Analytical Comparison of Remicade and the Biosimilar Remsima. Anal Chem 2o17, 89 (9), 48384846 .

26. Tian, Y.; Lippens, J. L.; Netirojjanakul, C.; Campuzano, I. D. G.; Ruotolo, B. T., Quantitative collision-induced unfolding differentiates model antibody-drug conjugates. Protein Sci 2019, 28 (3), 598-6o8.

27. Botzanowski, T.; Erb, S.; Hernandez-Alba, O.; Ehkirch, A.; Colas, O.; Wagner-Rousset, E.; Rabuka, D.; Beck, A.; Drake, P. M.; Cianferani, S., Insights from native mass spectrometry approaches for top- and middle- level characterization of site-specific antibody-drug conjugates. MAbs 2017, 9 (5), 801-811.

28. Botzanowski, T.; Hernandez-Alba, O.; Malissard, M.; Wagner-Rousset, E.; Deslignière, E.; Colas, O.; Haeuw, J.-F.; Beck, A.; Cianférani, S., Middle level IM-MS and CIU experiments for improved therapeutic immunoglobulin subclass fingerprinting. Anal Chem 2020, 92 (13), 8827-8835.

29. Sivalingam, G. N.; Yan, J.; Sahota, H.; Thalassinos, K., Amphitrite: A program for processing travelling wave ion mobility mass spectrometry data. Int J Mass Spectrom 2013, 345, 54-62.

30. Eschweiler, J. D.; Rabuck-Gibbons, J. N.; Tian, Y.; Ruotolo, B. T., CIUSuite: A Quantitative Analysis Package for Collision Induced Unfolding Measurements of Gas-Phase Protein Ions. Anal Chem 2015, 87 (22), 11516-22.

31. Migas, L. G.; France, A. P.; Bellina, B.; Barran, P. E., ORIGAMI: A software suite for activated ion mobility mass spectrometry (aIM-MS) applied to multimeric protein assemblies. Int J Mass Spectrom 2018, 427, 20-28.

32. Sivalingam, G. N.; Cryar, A.; Williams, M. A.; Gooptu, B.; Thalassinos, K., Deconvolution of ion mobility mass spectrometry arrival time distributions using a genetic algorithm approach: Application to alpha(1)-antitrypsin peptide binding. Int J Mass Spectrom 2018, 426, 29-37.

33. Polasky, D. A.; Dixit, S. M.; Fantin, S. M.; Ruotolo, B. T., CIUSuite 2: Next-Generation Software for the Analysis of Gas-Phase Protein Unfolding Data. Anal Chem 2019, 91 (4), 3147-3155.

34. Vallejo, D. D.; Polasky, D. A.; Kurulugama, R. T.; Eschweiler, J. D.; Fjeldsted, J. C.; Ruotolo, B. T., A Modified Drift Tube Ion Mobility-Mass Spectrometer for Charge-Multiplexed CollisionInduced Unfolding. Anal Chem 2o19, 91 (13), 8137-8146.

35. Ehkirch, A.; Hernandez-Alba, O.; Colas, O.; Beck, A.; Guillarme, D.; Cianferani, S., Hyphenation of size exclusion chromatography to native ion mobility mass spectrometry for the analytical characterization of therapeutic antibodies and related products. J Chromatogr B Analyt Technol Biomed Life Sci 2018, 1086, 176-183.

36. Polasky, D. A.; Dixit, S. M.; Vallejo, D. D.; Kulju, K. D.; Ruotolo, B. T., An Algorithm for Building Multi-State Classifiers Based on Collision-Induced Unfolding Data. Anal Chem 2019, 91 (16), 1040710412.

37. Konermann, L.; Ahadi, E.; Rodriguez, A. D.; Vahidi, S., Unraveling the mechanism of electrospray ionization. Anal Chem 2013, 85 (1), 2-9.

38. Kirby, A. E.; Jebrail, M. J.; Yang, H.; Wheeler, A. R., Folded emitters for nanoelectrospray ionization mass spectrometry. Rapid Commun Mass Spectrom 2010, 24 (23), 3425-31.

39. $\quad$ Eschweiler, J. D.; Martini, R. M.; Ruotolo, B. T., Chemical Probes and Engineered Constructs Reveal a Detailed Unfolding Mechanism for a Solvent-Free Multidomain Protein. J Am Chem Soc 2016, 139 (1), 534-540.

40. Liu, P.; Zhu, X.; Wu, W.; Ludwig, R.; Song, H.; Li, R.; Zhou, J.; Tao, L.; Leone, A. M., Subunit mass analysis for monitoring multiple attributes of monoclonal antibodies. Rapid Commun Mass Spectrom 2019, 33 (1), 31-40.

41. Kim, J.; Kim, Y. J.; Cao, M.; De Mel, N.; Albarghouthi, M.; Miller, K.; Bee, J. S.; Wang, J.; Wang, X., Analytical characterization of coformulated antibodies as combination therapy. MAbs 2020, 12 (1), 1738691 . 


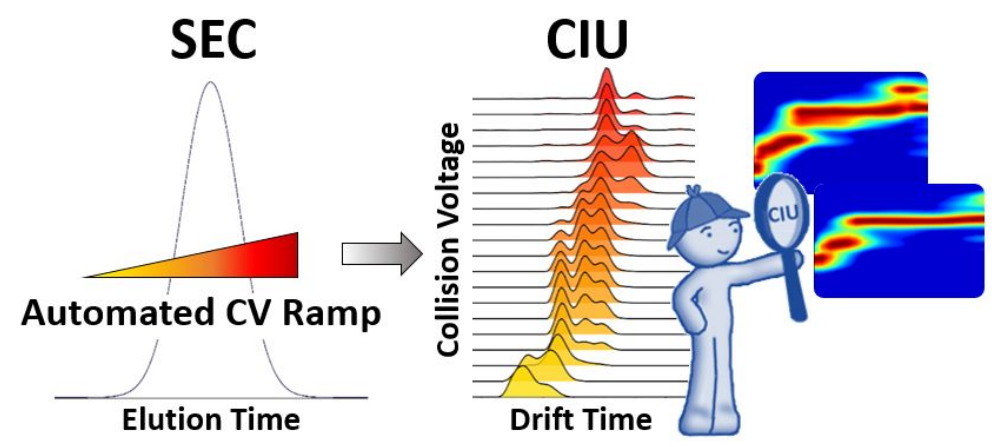




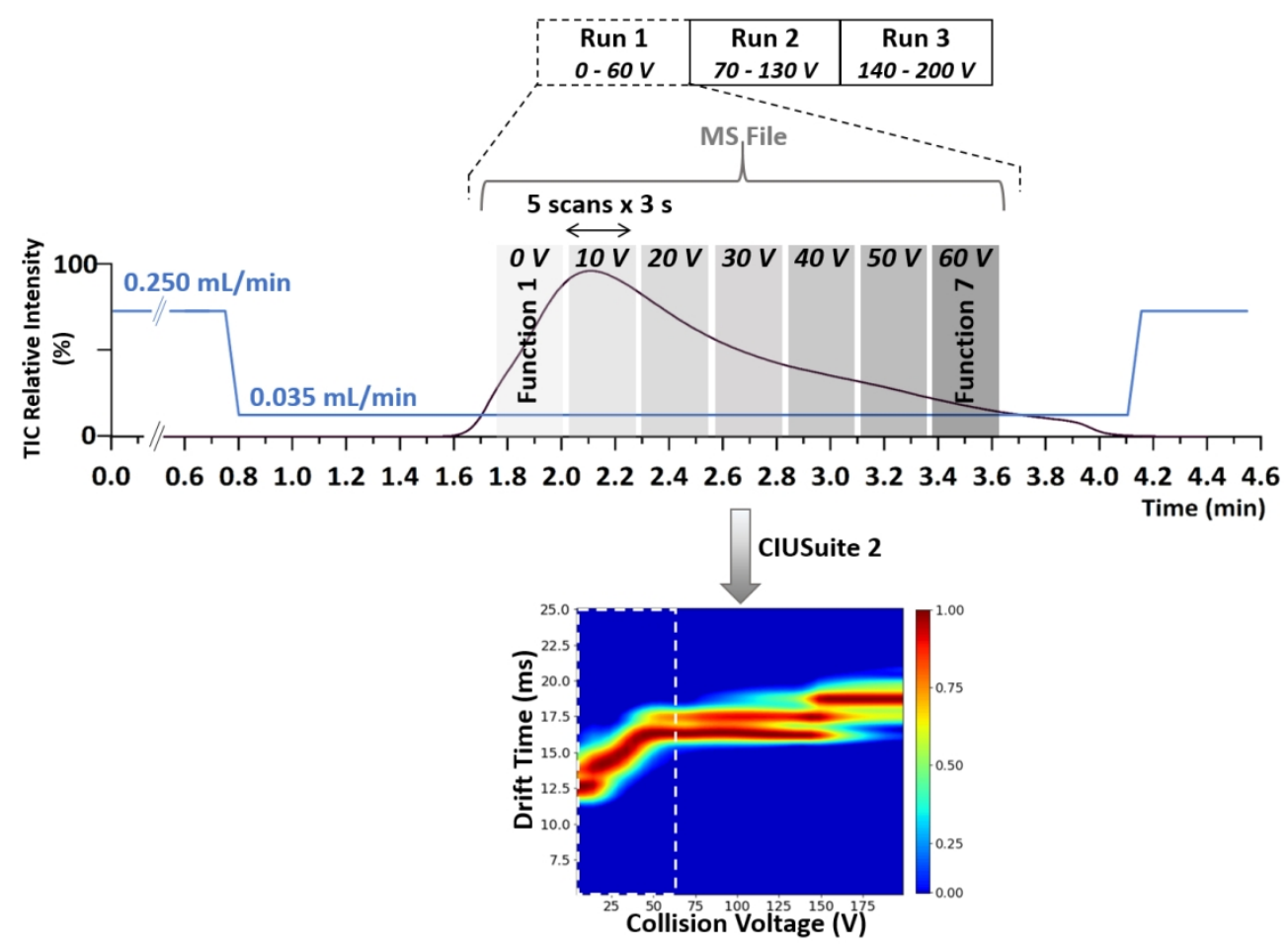

Figure 1. Schematic representation of the acquisition workflow of SEC-CIU data ( 0 - $60 \mathrm{~V}$ range) for intact mAbs. For each collision voltage, one IM-MS function (greyscale bar) is implemented in the MassLynx MS file along the sample elution. Scans parameters were set to 5 scans of 3 seconds each. A three-runs method was used to generate a complete CIU replicate $(0-200 \mathrm{~V})$. Averaged unfolding plots are generated from three replicates, illustrated here by the CIU fingerprint of the $26+$ charge state of adalimumab.

$250 \times 188 \mathrm{~mm}(150 \times 150 \mathrm{DPI})$ 

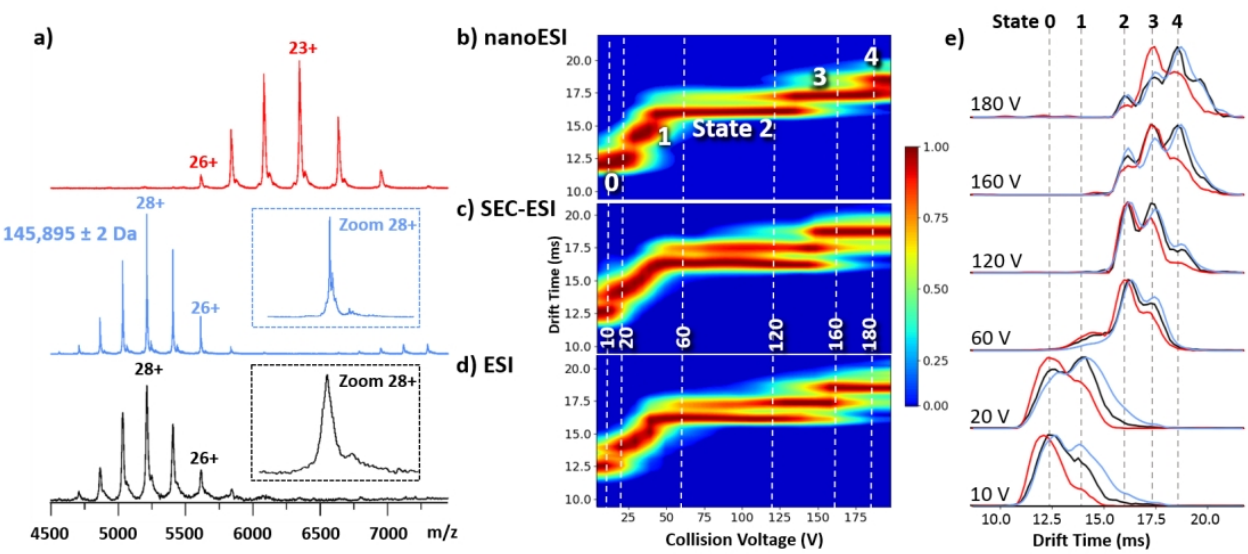

Figure 2. Comparison of nanoESI, SEC-ESI and ESI experiments. (a) Native mass spectra of intact adalimumab corresponding to nanoESI (red trace), SEC-ESI (blue trace) and ESI (black trace). Zooms on the $28+$ charge state are provided in insets for SEC-ESI and ESI mass spectra. CIU fingerprints of the 26+ charge state of intact adalimumab obtained with (b) nanoESI, (c) SEC-ESI and (d) ESI infusion modes. (e) ATDs extracted at different voltages for nanoESI (red), SEC-ESI (blue) and ESI (black) are depicted in the right panel.

$291 \times 135 \mathrm{~mm}(150 \times 150 \mathrm{DPI})$ 

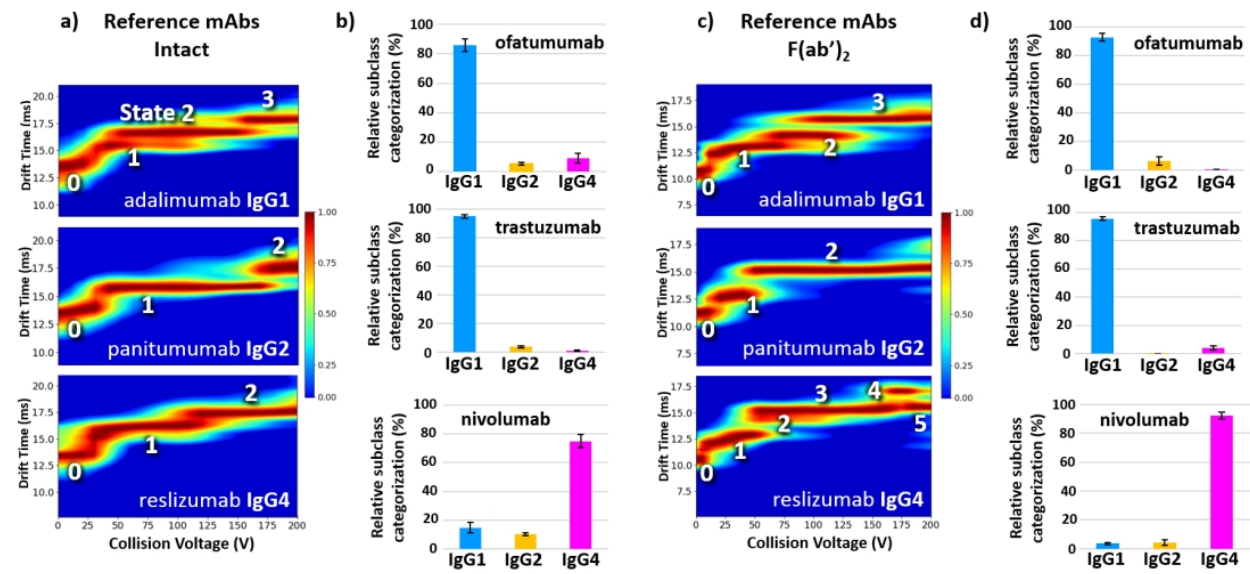

Figure 3. Intact and middle levels SEC-CIU experiments. (a) 27+ charge state fingerprints of our three reference mAbs, adalimumab, panitumumab and reslizumab. (b) Subclass classification $(z=27+)$ of ofatumumab (IgG1), trastuzumab (IgG1) and nivolumab (IgG4) obtained with our in-house intact level classification method. (c) $21+$ charge state fingerprints of $F\left(a b^{\prime}\right) 2$ fragments corresponding to our three reference mAbs. (d) Middle level subclass classification $(z=21+)$ of ofatumumab (IgG1), trastuzumab (IgG1) and nivolumab (IgG4).

$316 \times 149 \mathrm{~mm}(150 \times 150 \mathrm{DPI})$ 
a) ofatumumab $146,563 \pm 3 \mathrm{Da}$ panitumumab $144,755 \pm 2 \mathrm{Da}$

nivolumab $\quad 144,045 \pm 2 \mathrm{Da}$
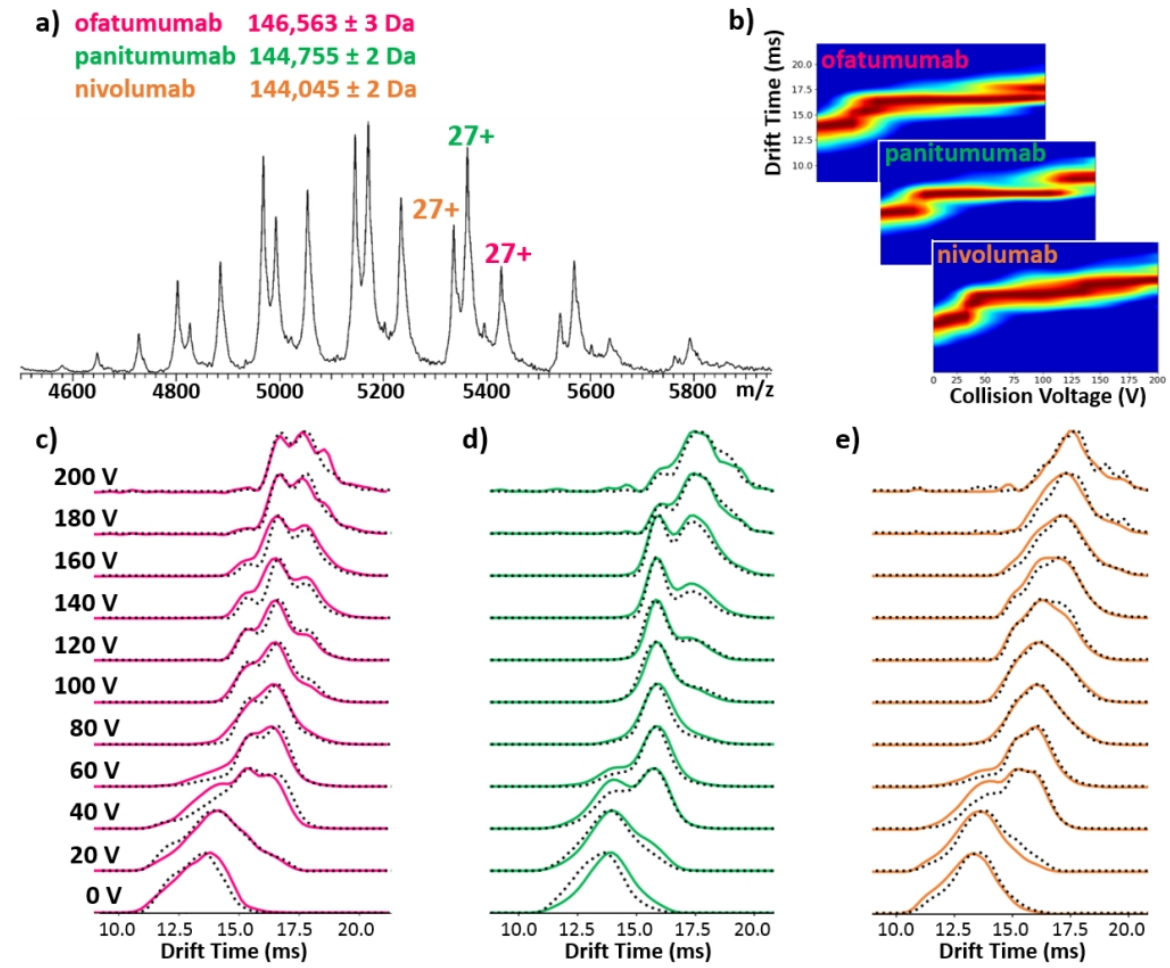

d)

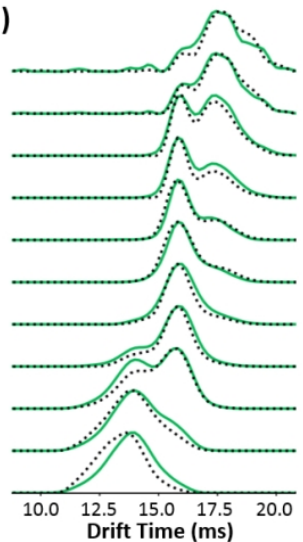

e)

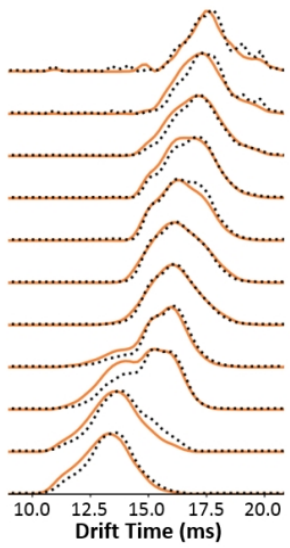

Figure 4 : MAbs-multiplexed SEC-CIU experiments. (a) Native SEC-CIU mass spectrum of an equimolar (15 $\mu \mathrm{M}) \mathrm{mAb}$ mixture containing three intact mAbs, ofatumumab, panitumumab and nivolumab (trap $\mathrm{CV}=90$ V). (b) 27+ charge state SEC-CIU fingerprints of each intact mAb subclass obtained from the mAb mixture. $(c, d$, e) ATDs were extracted in $20 \mathrm{~V}$ steps from 0 to $200 \mathrm{~V}$, allowing the comparison of unfolding processes of single-mAb (dotted lines) and mAbs-multiplexed SEC-CIU (solid lines) experiments at intact level.

$234 \times 189 \mathrm{~mm}(150 \times 150 \mathrm{DPI})$ 


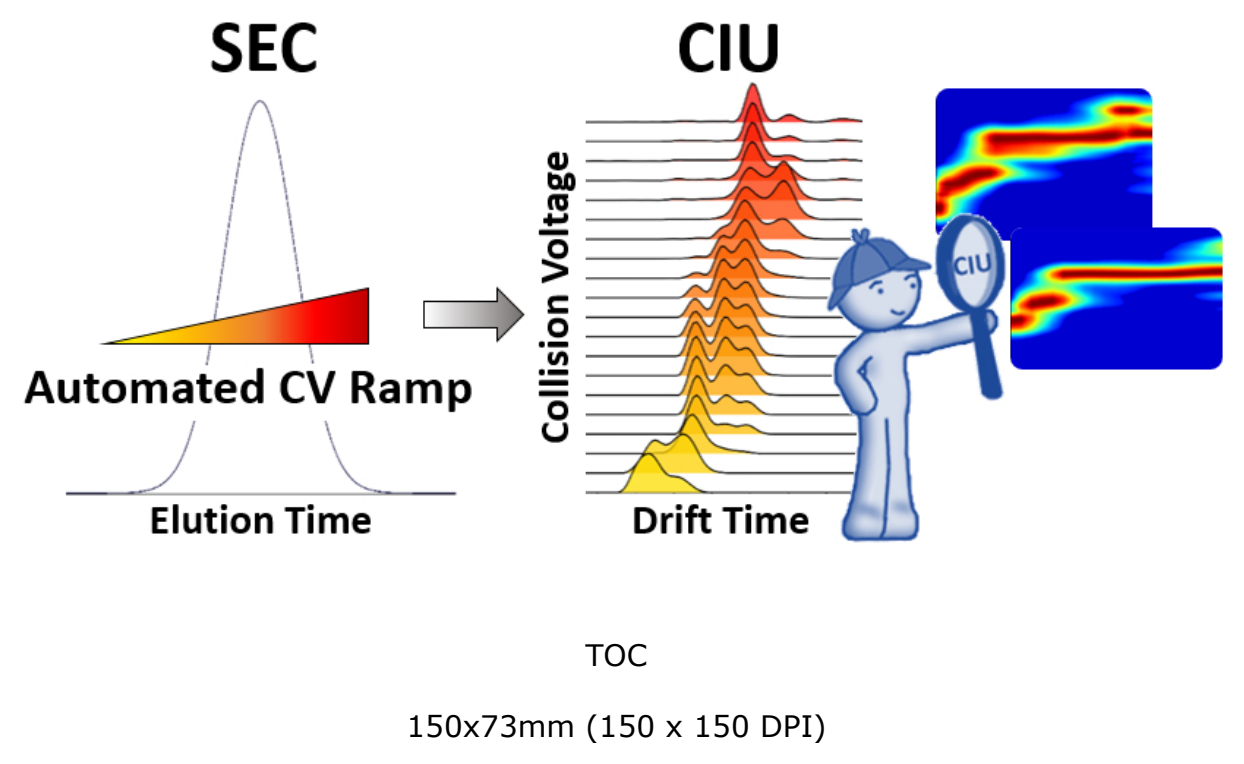

ACS Paragon Plus Environment 